\title{
A diferença que faz a diferença: originais e cópias Guarani-Mbya
}

La différence qui fait la différence : originaux et copies Guarani-Mbya

The difference that makes a difference: Guarani-Mbya original and copies

\section{Gustavo Godoy e Miguel Carid}

\section{(2) OpenEdition}

Journals

Edição electrónica

URL: https://journals.openedition.org/jsa/14643

DOI: $10.4000 /$ jsa. 14643

ISSN: $1957-7842$

\section{Editora}

Société des américanistes

\section{Edição impressa}

Data de publição: 31 outubro 2016

Paginação: 105-128

ISSN: 0037-9174

\section{Refêrencia eletrónica}

Gustavo Godoy et Miguel Carid, «A diferença que faz a diferença: originais e cópias Guarani-Mbya », Journal de la Société des américanistes [En ligne], 102-1 | 2016, mis en ligne le 02 décembre 2016, consulté le 02 septembre 2022. URL : http://journals.openedition.org/jsa/14643 ; DOI : https:// doi.org/10.4000/jsa. 14643 


\title{
A diferença que faz a diferença: originais e cópias Guarani-Mbya
}

\author{
Gustavo Godoy * e Miguel CARID **
}

\begin{abstract}
Partindo da análise estrutural de um conjunto de narrativas guarani-mbya em que o futuro Sol, Kuaray (ou seu pai Nhanderu), e o ogro Xariã são os protagonistas, o presente artigo explora a produtividade da oposição original/cópia na sociocosmologia mbya. Se Kuaray (ou Nhanderu) e as formas originárias se identificam com a divindade e com os Mbya, Xariã e as cópias exageradas pendem para o mundo excessivo dos brancos. O pensamento mítico mbya mobilizou os predicados associados às cópias exageradas para avaliar a experiência colonial. [Palabras-chave: Guarani, Mbya, Xariã, mitologia, cópia, colonização.]
\end{abstract}

La différence qui fait la différence : originaux et copies Guarani-Mbya. À partir de l'analyse d'un ensemble de récits qui confrontent Kuaray, le Soleil (ou son père Nhanderu), à l'ogre Xariã, cet article explore la prégnance de la tension original/ copie dans la socio-cosmologie mbya-guarani. Il expose d'une part comment les Mbya s'identifient à Kuaray, aux formes premières et à la part divine du monde et, d'autre part, comment ils associent Xariã et les copies au monde excessif des Blancs. L'article montre ainsi que les copies exagérées et les prédicats qui leur sont associés ont été mobilisés par les Mbya afin de prendre la mesure de leur propre expérience coloniale. [Mots-clés : Guarani, Mbya, Xariã, mythologie, copie, colonialisme.]

The difference that makes a difference: Guarani-Mbya original and copies. Using a structural analysis of a group of guarani-mbya narratives protagonized by the Kuaray (or Nhanderu) anda Xariã, this text looks into the diverse meanings of the duality original/copy, a fundamental pairing in the socio-cosmology of this people. If Kuaray (or Nhanderu) and their originary forms may be identified with divinity and with the Mbya, Xariã and the exaggerate duplicates, on the other hand, lean towards the excessiveness of the white man's world. The Mbya mythic thought evaluates the colonial experience through the use of the predicates associated with the exaggerated duplicates. [Key words: Guarani, Mbya, Xariã, mythology, copy, colonialism.]

* Programa de Pós-Graduação em Antropologia Social - Museu Nacional, Universidade Federal do Rio de Janeiro [gutzii@gmail.com] ; ** Programa de Pós-Graduação em Antropologia - Universidade Federal do Paraná [miguel@ufpr.br]. 
Nas páginas que se seguem retomamos algumas questões clássicas da bibliografia guarani - com foco nos Mbya - a partir da análise de um conjunto de narrativas que têm como operador estrutural a oposição entre criações originais e cópias excessivas ${ }^{1}$. Partindo de uma narrativa mítica que põe em cena Xariã, um ser negativamente valorizado e imitador por excelência, tentaremos rastrear a oposição entre originais e cópias mostrando que a função do universo excessivo (e perecível) da cópia pode ser pensada paralelamente à experiência colonial mbya. Trata-se, pois, de seguir a referencialidade recíproca entre mito e história. Por um lado, a temática eminentemente ameríndia do dualismo em contínuo desequilíbrio; por outro, o mundo colonial das Missões, apanágio das cópias, e o presente histórico, caracterizado pela proliferação serial, pelos excessos e as sucessivas tentativas de colonização ${ }^{2}$.

A motivação para escrever este texto surgiu de nosso interesse pela arte mbya, durante a elaboração de uma coleção de peças indígenas para o Museu de Arqueologia e Etnologia da Universidade Federal do Paraná (MAE/UFPR), após perceber que os Mbya qualificavam de modo contrastante, gráfica e eticamente, diferentes estilos da arte que produzem: por um lado, o artesanato destinado ao comércio, particularmente colorido e cheio de grafismos; por outro, os objetos que fabricam para si próprios, marcados pela sobriedade. Uma pesquisa mais profunda dessa polaridade tal e como se apresentava nas narrativas míticas, complementada com os registros etnográficos de diferentes grupos mbya, demonstrou sua recorrência em outras esferas da vida indígena para além do campo da arte.

É importante sublinhar que embora as narrativas míticas sejam o centro deste texto, nossa abordagem parte do entrelaçamento de categorias cosmológicas, avaliações morais e detalhes etnográficos cuja redundância aponta, justamente, para o valor ontológico das temáticas aqui discutidas: a relação entre originais e cópias (no campo dos desenhos, seres, características dos seres), a percepção do mundo não indígena e a avaliação da experiência colonial mbya, inseparável desse mundo. Obviamente, não pretendemos dar conta neste artigo de todas as

1. Este artigo se inspira na monografia de conclusão de graduação em Ciências Sociais (UFPR), Formas, cópias, regressões e fragmentações em mitologias ameríndias de Godoy (2011), orientado por Carid. Gostaríamos de agradecer a Oscar Calavia, Carlos Fausto e Eduardo Viveiros de Castro pelos generosos comentários feitos após a leitura de uma primeira versão deste texto. Agradecemos também aos avaliadores anônimos do Journal de la société des américanistes, cujas reflexões nos ajudaram significativamente no aprofundamento de vários argumentos. Obviamente, a responsabilidade das ideias aqui expostas é nossa.

2. Os Guarani são um dos povos indígenas das Terras Baixas da América do Sul mais numerosos e com maior presença territorial. Habitam diversas regiões no Brasil, Paraguai, Argentina, Uruguai e Bolívia. As estimativas demográficas anteriores a 2008 apontam os Guarani como o segundo povo mais numeroso no Brasil: 45.000 pessoas. Destas, 23.000 são Kaiowa, 12.000 Nhandeva e 10.000 Mbya (Ladeira 2008, p. 63). 
avaliações mbya relacionadas com esse processo histórico, pois sem dúvida existem diferentes contextos e interpretações da experiência colonial e do presente guarani, uns mais positivos, outros mais negativos, que podem se aproximar, distanciar ou até conviver com o recorte aqui referido. Nossa proposta é bem mais singela: relevar uma camada de sentido presente nos mitos, nos discursos e na moralidade mbya, extraída de uma diversidade de etnografias e narrativas suficientemente ampla para ser levada em consideração.

\section{Xariã: o funesto imitador}

Comecemos pois pela arte, por uma narração que põe em relação a origem da humanidade e de outros seres, os tipos de desenhos mbya e os cestos destinados para uso propriamente indígena ou para a venda aos não indígenas. A narrativa a seguir, recolhida por Valéria de Assis (2006) e narrada por Perumi, líder religioso e político mbya da Varzinha (Rio Grande do Sul/Brasil), articula de maneira bem definida a oposição entre criação original e cópia através das ações de Nhanderu e Xariã, respectivamente divindade e enganador ${ }^{3}$. Esta versão retoma o resumo feito por Assis (2006, p. 212-213) adicionando alguns elementos narrativos de outras partes de sua etnografia (ibid.: p. 247-250, 267, cf. 253).

Quando estava concluindo a criação do segundo mundo, Nhanderu Tenonde decidiu fazer um cesto (ajaka) de taquara e imbê para ser produzido e usado pelos Mbya. Ao fazê-lo aplicou-lhe motivos bem simples, com duas cores: para pyxyry ( "grafismo escorregado ») e pira raĩ nhykã ra 'angaa (« representação denotativa do maxilar do peixe $\left.{ }^{4} »\right)$.

Xariã, ao ver o que Nhanderu havia feito, tentou imitá-lo. Contudo, Xariã fez um cesto com motivos bem mais elaborados, associados à pele e à aparência de animais, notadamente às cobras, denominados representação ( $r{ }^{\prime}$ 'angaa) da cascavel ( $m b o i$ xinĩ), da jararaca (mboi jarara) e das asas da borboleta (tanambipepo).

Xariã ficou muito feliz com o que fez. Entretanto, Nhanderu, ao saber que havia sido imitado e que a imitação era muito diferente do que ele havia feito, ficou furioso. Nhanderu toma seu arco e golpeia o cesto uma vez; desta ação teve origem Guyrapa Rete ( « corpo de arco », isto é, o homem); tomando uma taquara, Nhanderu Tenonde golpeia o cesto pela segunda vez, dando origem, então, a Ajaka Rete (« corpo de cesto », ou seja, a mulher). Por fim, lançou um raio no diadema

3. Existem versões longas e sistematizadas das sagas de Nhanderu e de seu irmão, por exemplo, Cadogan (1997 [1959], p. 130-137) ou também a versão mais atual publicada em Gamba (2003, p. 59-103).

4. Para significa « enfeite com contraste entre claro e escuro »; - pyxyry « escorregar» (Dooley 2013, p. 136, 154). Assis indica que este grafismo é o mesmo que o chamado pararyxy- « grafismo enfileirado » (2006, p. 250, n. 151). Sendo que -(r)yxy significaria « em fila » (Dooley 2013, p. 172, 205). Os Mbya da Ilha da Cotinga (Paranaguá/Brasil) traduziram essa expressão como « desenho um atrás do outro » (comunicação pessoal da antropóloga Laura Pérez). Dolley traduz Pira raĩ nhykã como " maxilar de peixe » (ibid., p. 143, 174). 
de Xariã, que correu para espantar o fogo destruidor de seu diadema. Enquanto corria, as cinzas que saíam das chamas do cocar transformaram-se em insetos que picam e incomodam os humanos.

Essas formas de cestaria foram herdadas pelos Mbya, sendo produzidas atualmente por estes. A cestaria cuja forma foi elaborada por Nhanderu é bela e boa, deve ser elaborada para o autoconsumo; ela não se presta a virar mercadoria, artesanato. A cestaria cujo modelo foi produzido por Xariã possui outro valor e pode ser mercadoria - isto é: artesanato para venda.

Segundo a etnografia de Assis (2006, p. 212, 247-249), cujas informações provêm principalmente dos Mbya que habitam no leste do Rio Grande do Sul, Xariã é burlesco, estabanado, solitário, atrapalhado, embora sábio. Ele é considerado o oposto de Nhanderu Tenonde - que tem esposa e filhos -, mas tem poderes semelhantes aos dele. Enquanto Nhanderu pretende criar boas condições para os Mbya, Xariã é o responsável pelas condições adversas de existência.

O primeiro ponto a se destacar é o próprio nome, pois em nosso sobrevoo bibliográfico não percebemos que Xariã apresente cognatos em outras línguas guarani. Na maior parte dos registros esse personagem é designado por cognatos da palavra Anhã (traduzido de diversas maneiras, inclusive como « diabo »), que por sua vez possui cognatos em várias línguas tupi-guarani. Aliás, a negatividade e a importância cosmológica de Xariã entre os Mbya nos parecem mais marcadas do que entre os seres equivalentes presentes nas narrativas de outros povos tupi-guarani. De modo geral, destaca-se seu caráter antissocial e solitário, sua fala confusa, o caráter lascivo, seus vínculos com o incesto, com a origem da gemelaridade e com a parcela telúrica ${ }^{5}$ que compõe a pessoa mbya.

Os registros desse caráter antissocial nas etnografias mbya são abundantes. Para não estendermo-nos em excesso citaremos apenas alguns. Na aldeia de Estiva em Viamão (Rio Grande do Sul, Brasil), por exemplo, as pessoas que ficam sozinhas são comparadas com Anhã (Stein 2009, p. 265). Segundo Vera Mirim, cacique da aldeia mbya de Bracuí no Rio de Janeiro, e Timoteo Karai Mirim, as pessoas incestuosas pertencem a Anhã e vão para sua morada quando mortas (Litaiff 1999, p. 300-301). Afirma-se também que a gemelaridade é fruto das ações de Anhã: sendo um dos gêmeos filho do ogro, cabe então desfazer-se de um dos irmãos para evitar a morte dos pais. É por isso que Alcindo Karai, xamã de Mbiguaçu (Santa Catarina, Brasil), relatou que mulheres grávidas não podem ter relações sexuais, pois esse ato poderia provocar que elas viessem a ter outra criança, filha de Anhã (Litaiff 1999, p. 304-305). Igualmente, outros Mbya contam que Anhã pode enviar o princípio vital que anima a pessoa no

5. Para os Mbya, os humanos têm uma « parte dolorosa » reificada em uma alma de origem terrestre, «telúrica ». Congruente com a antissocialidade, esta alma é produto de um modo imperfeito de existência e se relaciona tanto com a origem de espectros dos mortos (Cadogan 1997 [1959], p. 305), como com o princípio maligno que gera a gemelaridade (Assis 2006, p. 97). 
caso de concepção de gêmeos (Mello 2006, p. 256-257). Interlocutores mbya do Rio de Janeiro - como Amarildo, da aldeia de Niterói, e Santo, de Mamanguá em Paraty - afirmam que a parte terrestre da alma (teteregua) tem sua origem em Anhã (Pereira 2010, p. 95). Cirilo de Yvytuko, Mbya do Paraguai, explica a origem da alma telúrica (mbogua), que se incorpora na alma de procedência celeste, correlacionando-a com Xariã. Conforme registra Cadogan, esta alma-espectro apareceu pela primeira vez quando a filha de Nhanderu Pa'i, descumprindo a ordem de seu pai, olhou para os Tupã rekoe (os agentes da destruição ${ }^{6}$ ) e, assim, a menina morreu e se fez mbogua - estes Tupã rekoe surgiram da alma de Xariã (1997 [1959], p. 136-137, 143).

Como descreve Mello, Anhã/Xariã pode possuir também uma localidade própria (2006, p. 256-257). Acima da terra atual, designada como yvy vai (terra má), encontra-se Anhã yvy: terra de Anhã. Esta terra é similar a yvy vai - a terra atual, localidade das formas decadentes e perecíveis - e nela moram Anhã e seus parentes, que são agentes de destruição e perecimento. Eles contaminam yvy vai em oposição a outros planos acima desta terra em que os seres são imperecíveis, incluída aí a terra de Anhã e seus parentes. Os moradores de Anhã yvy podem circular por yvy vai. Os humanos, moradores de yvy vai, podem caminhar por Anhã yvy em sonhos ou viagens com tabaco ou ayahuasca, correndo-se o perigo de ser capturado pelo povo de Anhã yvy. Em yvy vai, Anhã criou as cobras venenosas. Andrés, Mbya do Uruguai, relata que o ogro Xariã pode confundir os sonhos (Rodríguez 2003, p. 253).

Na versão mbya do Paraguai recolhida por Cadogan (1997 [1959], p. 135), a ênfase não recai na capacidade imitadora de Xariã, mas em seus modos excessivos. Em vez de copiador de cesta com formas exageradas, como na versão anterior de Perumi, Xariã aparece como tomador de uma noiva feita de cesto que tem para com ela um modo exagerado de se relacionar. Lascivo em grau máximo, Xariã acaba por transformar a mulher para sempre em um cesto. « Después de este hizo Nuestro Padre Pa'i a su futura hija de un canasto. La Dio a Chariã y él la llevó y fornicó con ella por el camino, destrozándose el pene. Castigó por eso Chariã a la mujer, y sin más volvió a convertirse en canasto » (ibid., p. 134-135).

Este modo lascivo, exagerado, é caracterizado na versão de Misiones deste mesmo mito como próprio dos não indígenas. Esta narrativa enfatiza que o modo lascivo remete ao comportamento de um verdadeiro « extranjero (paraguayo, cristiano) », isto é, um não indígena, um jurua. Assim, Xariã agiu segundo um modo realmente não indígena (Gamba 2003, p. 90). Outro mito que liga Xariã aos não indígenas o identifica com o violão (mbaraka pytã). Quando Xariã cansou da dança cerimonial e caiu, seu instrumento também caiu. Nhanderu Pa'i Rete

6. Cadogan dá mais uma definição desses Tupã rekoe: « los que podían denominarse dioses menores. El padre de ellos es el alma de Chariã, rival del héroe solar » (2011 [1992], p. 181). 
Kuaray analisou e viu que era bom - mas tirou uma corda do violão, deixando-o com cinco cordas, ao contrário dos violões dos não indígenas, que geralmente têm seis. Desde então o violão é um instrumento musical dos Mbya (ibid., p. 80, 83).

Além do fato já apontado de Xariã falar incorretamente, de um jeito grotesco e trocando palavras, com um guarani mal articulado, ele também pode responder inadequadamente. Em um jogo de adivinhações com Nhanderu Pa'i Rete Kuaray, ao ser questionado sobre o que seria « aquello que degusta lo comido », Xariã, « de puro antipático », não disse « a boca », a resposta em sentido próprio, mas respondeu figuradamente: « el pene erecto $^{7} »$ (ibid., p. 85).

\section{Os dois estilos}

A oposição de « estilos » entre as mercadorias e os bens produzidos para uso próprio indicada na narrativa procedente do Rio Grande do Sul é a mesma mencionada pelos Mbya de São Paulo, junto aos quais Ladeira observou que os objetos cotidianos e rituais, que não eram vendidos, tinham um estilo diverso daqueles que se tornavam mercadoria: « Muito mais simples, sem os adornos e as cores vibrantes, destina-se exclusivamente ao uso da comunidade. Somente sob encomenda, para museus ou exposições, os Guarani fabricam as peças (pilões, bancos, colares, maracás, cachimbos, cestos) que são vendidas novas, sem uso » (Ladeira 1984, p. 144).

Assim, entre os Mbya, a oposição original versus cópia que corresponde à dualidade atual, como narrou Perumi, autoconsumo versus mercadoria, se materializa em critérios estéticos bastante definidos: os grafismos da cestaria de Nhanderu são caracterizados majoritariamente como para, sendo a cesta em que são trançados simples e contida, ao passo que os desenhos de Xariã são qualificados de - $a$ 'angaa, cestas coloridas e com formas exageradas. Vejamos então um pouco mais de perto os sentidos dessas palavras, pois eles encerram algumas particularidades significativas para o tema que nos ocupa.

Segundo Dolley, o lexema para significa « enfeite com contraste entre claro e escuro » (2013, p. 141). Ele é tanto um nome, como na predicação para ryxy « grafismo enfileirado » ou na relação genitiva mboi para « grafismo de cobra », quanto um adjetivo, como no nome da cestaria antiga, feita de taquara e cipó imbê: ajaka para (Cadogan 2011 [1992], p. 133). Mas é possível também

7. Lévi-Strauss apontou para a relação de homologia estrutural entre, de um lado, o incesto e a pergunta onde é postulado que não haverá resposta, mas que contra esta expectativa é respondida; e, de outro, entre a castidade e a resposta para a qual não houve pergunta (2012 [1973], p. 33). Trata-se aqui de um intermediário, uma pergunta para a qual é postulado que se dará uma resposta correta (ou seja, no sentido próprio), mas, contra a expectativa, é respondida de modo figurado, uma resposta similar embora excessiva. Esta forma de responder o enigma estaria correlacionada a um comportamento sexual excessivo, embora neste caso não incestuoso. 
verbalizá-lo mediante o prefixo causativo « mo- » significando « adornar (canastas, etc.) ou manchar» (ibid., p. 111).

Os significados associados a para em língua mbya levantam interessantes perguntas de semântica diacrônica da família linguística tupi-guarani. O significado « manchar », mais difundido nas línguas tupi-guarani, aparece também ligado a outros significados que indicam « diversidade de cores » e, fora do campo semântico das cores, « misturar » ou " variedade de coisas ». Esses cognatos contrastam com o valor de para em mbya, que enfatiza o contraste e não a mescla $^{8}$. Em tupi antigo ${ }^{9}$ (ramo 3) parab significa « manchado, multicolor », paraba é « variedade, diversidade ». Quando verbalizado com o causativo " $m o$ - » e com o recíproco « $\hat{\imath} o$ » mồoparab, corresponde a « intercalar, misturar » (Navarro 2013, p. 293, 371). A mistura dos idiomas português, espanhol e guarani paraguaio é chamada de jopará, em guarani. Em araweté (ramo 5), parawï parece manter esse campo semântico: yiri parawï « boca travada ou misturada » está em oposição a yirì kara kato « boca correta ou hábil », sendo que os Araweté afirmam de si mesmos: ire parã we « somos todos misturados » (Viveiros de Castro 1986, p. 146, 263; cf. p. 366, 435). Na língua ka’apor (ramo 8), aparentemente só restou a forma causativa mupara, com o significado de « misturar» (Kakumasu e Kakumasu 2007 [1988], p. 60, 126, 179).

Poderíamos nos perguntar se a importância do contraste é uma inovação semântica mbya, tendo em vista a comparação com o guarani antigo registrado pelo padre Montoya no século XVII: « Pará. b. Variedad. Aópará, vestido de colores. Mbaeîopárá arecó, tengo cosas varias. Abápára, hombre houero pintado » (Montoya 1639, p. 263). Para « pintar de várias cores » a forma causativizada do morfema tinha que ser somada ao verbo yquatiábo, trazendo a ideia de adornar ou grafar (dizendo ambopárá yquatiábo), que, portanto, não era marcada em guarani antigo como é o caso em mbya contemporâneo.

A importância da dimensão contrastiva veiculada pela palavra para em mbya encontra sua confirmação no mito contado por Perumi, na medida que para também pode ser entendido como uma representação não figurativa, enquanto - a'angaa seria uma representação figurativa que se usa para referir-se à fotografia. Como apontou Assis: « Essa distinção torna-se clara quando o Mbyá João Paulo [filho de Perumi] utiliza essas categorias para diferenciar escrita e fotografia, sendo a primeira entendida como para e a segunda como ra'anga » (2006, p. 257). A autora aponta também para a oposição escuro contrastando com claro como definidor de para.

Podemos concluir então que para se refere a uma noção de contraste (tal como justaposição do branco e do preto), que alude a uma forma sóbria e moderada,

8. No caso dos Mbya, a ideia de multiplicidade parece ter sido desvalorizada e, como comentaremos mais à frente, o morfema -vai pode significar também «maldade » e « excesso ».

9. Classificações segundo Rodrigues (1984-1985). 
enquanto - $a$ 'anga designa uma semelhança figurativa, uma iconicidade de valor excessivo. Ademais, o original é relacionado com o discreto enquanto a cópia com o contínuo, já que sua iconicidade aproxima o referente do significante e sua forma aproxima diversas cores entre si. Como veremos à continuação, esta oposição também está presente em uma versão mbya do mito de origem dos animais.

\section{Seres originais, cópias venenosas}

A narrativa de Perumi sobre a origem da cestaria não é a única que atualiza a importância da dialética entre original (de forma sóbria, com contrastes e não figurativa) e cópia (de figuração excessiva, ou misturada, e icônica). Uma versão narrada por Davi Martins da Silva, Karai Tataendy, no litoral de São Paulo (Ladeira 2007), e outra de Lorenzo Ramos em Misiones (Gamba 2003), especulam sobre as diferenças morfológicas e ontológicas entre plantas, animais e peixes. Ambas narrativas introduzem a relação entre originais e cópias, bem como o papel imitativo de Xariã, criador dos seres ferozes, perigosos, de formatos acentuados, identificados com os não indígenas ou provenientes de regiões distantes.

No primeiro mundo foram geradas as criações de Nhanderu para os Mbya. Entre as plantas estavam: o milho verdadeiro, o jaracatiá, algumas espécies de banana, a mexerica, yvyra 'a (planta usada para tingir os cabelos), o mel, o cipó embé, a embira, yvaũ (semente preta utilizada como conta), o capiá, o jerivá. Entre os animais ele criou: yxo (larvas de coleópteros), queixada, tatu, quati, onça pintada, onça preta, sucuri, cobras de diversas espécies não venenosas, tucano, jacu, papagaio, nhambu, certas corujas, colibri, a galinha silvestre (uru'i). Entre os peixes bons (pira porã) ou permitidos: o bagre, a tainha, o lambari, o peixe branco, as carpas brancas.

Anhã quis ser mais criativo, quis inventar mais coisas: baseou-se nas criações de Nhanderu, exagerando suas formas e cores. Entre as plantas, inventou as raízes coloridas, como a beterraba e a cenoura; as verduras, como a couve, o repolho e outras folhas que são a imitação das plantas e ervas dos matos usadas como remédio; os palmitais, vários tipos de bananas, como a banana nanica e a banana maçã; o milho híbrido. Também são de sua autoria a manga, o abacate, a jaca, o abacaxi, o limão, várias espécies de laranja, árvores como o eucalipto e o pinheiro.

Entre os animais, Anhã gerou, sobretudo, os ferozes, entre os quais: as cobras venenosas, diversas aves e felinos. Também criou os animais de criação dos brancos: galinhas, gado, porcos, cavalos, bem como os animais de outras regiões, como leões, tigres, girafas e zebras. Inventou também diversas criaturas da água e peixes impuros. São os peixes maus (pira vai) ou proibidos: as carpas coloridas e todos os peixes com formatos acentuados. Quando viu a aranha (nhandu) não venenosa, criou outros tipos e o caranguejo (nhandu vai). Também criou o camarão e a lagosta.

A narrativa termina explicando como Anhã criou o cação, o tubarão e as baleias: «Anhã quis criar o maior peixe do mundo. Então ele pegou a carne de todos os peixes e até dos próprios corpos humanos. E pegava um pedaço da carne de cada peixe. Pegou depois das aves, das galinhas, dos porcos, das cobras, e assim juntou 
a carne de vários animais que não deveriam ser misturados. E assim criou o maior peixe do mundo ». (Baseado em Ladeira 2007, p. 157-158)

A versão de Misiones por Lorenzo Ramos conta o seguinte:

Xariã ia acompanhando Kuaray, nosso pai Sol. Nosso pai quis que o mel fluísse constantemente de todas as árvores, mas Xariã disse que não seria assim, que os humanos deveriam buscar o mel constantemente para coletá-lo. Nhanderu fez a abelha jataí, que não tem ferrão e de cujas pequenas vasilhas se extrai um mel doce que também serve de remédio para o umbigo das crianças. Xariã também quis fazer esta abelha, mas não saiu da mesma forma: criou a vespa amarela, que tem uma picada muito doída.

Sol quis que todas árvores dessem frutos comestíveis. Xariã olhou para isso e disse que assim todas as pessoas seriam imprestáveis, abatidas.

Nhanderu Pa'i quis que as plantas cultivadas já estivessem com frutas, raízes e sementes no dia seguinte de sua plantação. Xariã disse que não era assim que deveria ser, que deveríamos esperar muitas luas para elas estarem boas para o uso. Nhanderu Pa'i criou o muçum; em contrapartida Xariã criou as cobras venenosas.

Nhanderu Pa'i levantou um jerivá para que os humanos comessem suas frutas alaranjadas e as larvas brancas que nascessem na árvore. Então Xariã também tentou em vão fazer o jerivá (Syagrus romanzoffiana), mas o que fez foi o mucajá (Acrocomia sp.), uma palmeira cheia de espinhos, que iam desde o solo até sua ponta.

Nhanderu Pa'i criou a laranja verdadeira e, querendo fazer o mesmo, Xariã criou as laranjas amargas. As verdadeiras laranjas estão no paraíso de Nhanderu, sendo que a laranja que existe nesta terra é somente uma imagem (-a'angaa) da original. (Baseado em Gamba 2003, p. 74-79)

Ambas narrativas contêm uma série de homologias muito significativas entre os seres criados por Nhanderu e os que resultaram da atividade imitativa de Xariã, resumidas na tabela abaixo.

\begin{tabular}{|c|c|}
\hline Criações de Nhanderu & Cópias de Anhã \\
\hline Simples & Extravagantes, exageradas \\
\hline Abundância & Dispersão, demora \\
\hline Neutras & Acentuadas \\
\hline (Para os) Mbya & (De criação dos) jurua \\
\hline Espécies locais & Espécies distantes, estrangeiras \\
\hline Dóceis & Ferozes \\
\hline Inócuas & Venenosas \\
\hline Formas apropriadas & Misturados \\
\hline
\end{tabular}

É de se destacar que a intensificação do tamanho, origem dos grandes peixes (tubarões e baleias), se produz mediante uma acumulação de carnes misturadas 
de diversas origens - um procedimento de acumulação cromática. A armação que examinamos nas páginas anteriores, baseada numa « codificação estética », se mantém, mas agora é aplicada em outros planos: « zoológico », « botânico » e « dos peixes ». Assim, como há dois « estilos » de cestaria, coexistentes na produção atual dos Mbya, há dois « estilos » de animais, peixes e plantas. Embora haja especificidades nas duas versões, todas se sustentam em um esquematismo de dualidade não paritária com uma forte significação moral. Há cestos moral e esteticamente inferiores; há animais, plantas e peixes superiores; outros, inferiores.

\section{Dualidades e cromatismos}

As narrativas mbya afirmam que a « boa forma »-o estilo de cestaria e seres com poucas cores contrastando, grafismos simples e formas simples - não é somente moralmente superior como é anterior ao estilo «cromático ». A variedade de cores, as formas e os grafismos excessivos foram obra de Xariã/ Anhã, que através da cópia exagerou o estilo e as criações precedentes de Nhanderu. Com efeito, entre os Mbya, os modelos de boas cestas - aquelas para autoconsumo -, bons animais, boas plantas e bons peixes são qualificados de « moderados » e « sóbrios ». É por um exagero destas formas e pela criação de uma cópia deturpada, cromática, que se produzem as formas que não são próprias para autoconsumo.

Este desenvolvimento moral dos mitos mbya pode ser melhor delineado quando contrastado com a « peça cromática » e o " concerto dos pássaros » estudados no primeiro volume das Mitológicas por Lévi-Strauss (2004 [1964], p. 295-323, 343-362). Como se lembrará, tratando da origem da cor das aves, e em geral de outros animais, este ciclo põe em cena a fragmentação do corpo de uma Cobra Grande multicolorida. Esses relatos, bastante difundidos entre os povos indígenas da América do Sul, abordam a origem das doenças e do veneno de pesca operando uma passagem e uma articulação de uma série original, que se pode caracterizar como cromática ou contínua, a uma série diatônica ou discreta.

O primeiro fato a destacar dessa comparação é que os relatos mbya invertem a lógica que opera no conjunto de narrativas analisadas em $O$ cru e o cozido - exceto no mito vilela (M 173) que comentaremos abaixo. Da fragmentação de um corpo cromático primitivo, no caso das conhecidas narrativas da cobra multicolorida, passa-se nas narrativas mbya ao exagero interno de um corpo discreto primitivo. É pela ação do ser copiador que se geraram as formas excessivas, cromáticas. O cromatismo, portanto, não é dado, mas derivado; ele representa uma série que replica, de maneira perversa, a série discreta inicial e virtualmente favorável à existência mbya, como vimos na oposição dos grafismos para e -a'angaa e na narração das diferentes qualidades de plantas e animais.

Esta inversão do sistema mítico da Cobra Grande não é arbitrária. De fato, uma variação do modo de operar deste grupo de narrações se encontra em um mito 
mbya relativo não a uma cobra cujas partes fragmentadas são a causa material da diferenciação entre os pássaros (e o estabelecimento de uma perspectiva destes diferente da perspectiva dos humanos), mas a um pássaro. O pássaro, ele próprio insumo de uma fragmentação, substitui o código visual da plumária pelo código auditivo dos cantos. Lembremos, entretanto, que se várias versões do mito de fragmentação da cobra multicolorida originam as cores da plumária e não os cantos, tal tema não está completamente ausente. Na versão arekuna (ibid., p. 301-302, 346) os animais recebem também nesta ocasião suas flautas, que definem a especificidade de seus cantos, acontecendo o mesmo na narrativa vilela. A passagem do código visual para o código auditivo permite construir uma ponte com a narrativa que recolheu Cadogan e que apresentamos na tabela abaixo (1997 [1959], p. 218-219):

\begin{tabular}{|c|c|}
\hline $\begin{array}{l}\text { Habiendo terminado de crear } \\
\text { las selvas creó Nuestro Padre } \\
\text { (Nhanderu), dicen, un ave de } \\
\text { maravilhoso cantar, el guyra } \\
\text { rembykyra'e'eỹ. }\end{array}$ & $\begin{array}{l}\text { Ka'aguy ojapopámavy, } \\
\text { Nhanderu, ombojera araka'e } \\
\text { Guyra Nhe'éngatu, guyra } \\
\text { rembykyra'a'eỹ. }\end{array}$ \\
\hline $\begin{array}{c}\text { Soltándolo en los bosques, cató } \\
\text { simulando una multitud de } \\
\text { pájaros. }\end{array}$ & $\begin{array}{c}\text { Opoi ka'aguy re, onhe'ẽ guyra } \\
\text { vaipa a'e rami. }\end{array}$ \\
\hline $\begin{array}{l}\text { Las urracas y también el mba- } \\
\text { tovi; imito a los pájaros en su } \\
\text { totalidad. }\end{array}$ & 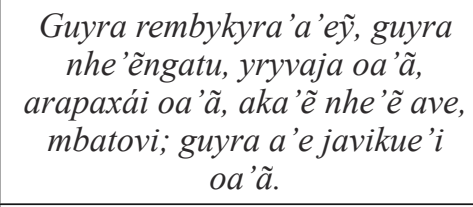 \\
\hline $\begin{array}{l}\text { Después de esto: « No es nada } \\
\text { bueno que haya una sola clase } \\
\text { de pájaros », dijo Nuestro Padre. } \\
\text { Por dicho motivo, Nuestro } \\
\text { Padre, de su divinidad, creó } \\
\text { una multitud de pájaros, cuyos } \\
\text { cantos se escucharon en toda la } \\
\text { extensión de la selva. }\end{array}$ & $\begin{array}{c}\text { A'e gui katu: "Nda'evei a'e } \\
\text { guyra peteĩ i oiko anguã », e’i } \\
\text { Nhanderu. A'éva rema katu, } \\
\text { omarã'ẽ̃ gui Nhanderu ombo- } \\
\text { jera guyra kyrĩ eta, ka'aguy jave } \\
\text { rema oñeendu. }\end{array}$ \\
\hline
\end{tabular}

Cadogan indica que a ave mítica original é similar à calândria, ou seja, pertencente às espécies da família Mimidae, presentes na região e caracterizadas pelas suas capacidades imitadoras: o sabiá-do-campo (Mimus saturninus) ou a calhandra-de-três-rabos (Mimus triaurus). Como Xariã, o pássaro é um imitador exemplar ${ }^{10}$, comparado com a cobra multicolorida, ele opera no registro da codificação auditiva dos cantos em vez do registro das cores.

10. Dolley traduz - $a$ 'ã por « imitar », « arremedar » e menciona também que alguns falantes usam o verbo - a'anga em vez de - $a$ 'a , no sentido de medir (2013, p. 27). 
Este aspecto de guyra rembykyra'e'ery, que podemos chamar sua « função cromática », é um pouco mais complexo de circunscrever. Para começar, devemos considerar que guyra rembykyra'e'eỹ imita de um modo muito singular, pois seu canto inclui uma «multidão » (vaipa). No livro Ayvu Rapyta, Cadogan traduz essa palavra por « multitud » (multidão) e ainda usa « totalidad » (totalidade) para o termo javikue. Vai-pa resulta da combinação de $p a$, que significa « tudo », com vai, que além de mal, disforme, irritado, significa « muito e uniformemente ». Como já comentamos, o sentido de « mal», « ruim »é correlacionado a «muito e uniformemente » através da valorização mbya do contraste e a diferenciação. Por sua vez, Cadogan traduz o termo javikue em seu dicionário mais atual por « iguales, muchos », " totalidad-semejante » ( « iguais muitos », « totalidade-semelhante »), o que parece colocar a multidão do lado do cromatismo e do contínuo: quando os pequenos intervalos viram uma multidão de iguais produz-se uma totalidade já próxima à indistinção. Nesse sentido, o pássaro guyra rembykyra 'a 'eỹ, prefigurando a totalidade de cantos da floresta, é uma variante das cobras de escamas cromáticas, que prefiguram as plumárias das diversas aves.

A referência cromática do pássaro radica não só na dedução empírica da qualidade sonora do canto, mas no fato de reunir em um corpo (de uma ave) o que se antevê como separado e diversificado: as diferentes espécies de pássaros incluídas nessa unidade por antecipação de seus cantos que, depois, de certo modo origina. Esse pássaro é um perfeito imitador, mas o é de uma forma muito singular, colapsando a diversidade na unidade, o que não pareceu bom aos olhos de Nhanderu.

Essa operação lógica não parece diferente à descrita por Lévi-Strauss quando analisa um mito vilela mencionado acima (2004 [1964], p. 347), em que um menino se transforma em um ser cromático cujo brilho é visto na escuridão da noite: « Isso acontece depois de ele (o menino) ter recolhido à beira da água pedras de cores diversas e ter feito delas um colar, ou seja, um ser multicolorido formado de elementos anteriormente dispersos, e entre os quais, a partir do momento em que são aproximados pelo fio, os intervalos se tornaram muito pequenos » (ibid., p. 364, destaque nosso). No caso da narrativa mbya, poderíamos dizer que o fio é o próprio pássaro e seu canto.

A favor da aproximação com a mitologia da Cobra Grande, observemos também que no mito vilela (M 173), o menino de comportamento antissocial transforma-se na cobra canibal depois de fazer um colar de miçangas combinadas cromaticamente. Lévi-Strauss chama a atenção sobre o fato de o colar não existir etnograficamente, dizendo que « seria difícil, cremos, descobrir um colar que corresponda a essa descrição nas coleções etnográficas provenientes da América tropical, cujos colares se caracterizam por suas cores sóbrias e sua regularidade » (ibid., p. 364). Este colar especulativo do mito vilela tem características formais similares à cestaria mercantil mbya, idealizada por Xariã. 
Assim sendo, tudo se passa como se os Mbya realizassem no plano técnico o que seus vizinhos chaquenhos deduziram mitologicamente, podendo a cestaria e os grandes animais serem descritos segundo as narrativas mbya da mesma forma que o colar do mito vilela.

O canto cromático (alhures, partes cromáticas de Cobras Grandes) é o ponto de partida da diferenciação dos cantos (que são homólogos da plumária) distintivos das espécies, bem como a recusa de Nhanderu da unidade (cromática) dos pássaros (e da imitação grotesca) é sua motivação. A especificidade mbya se deixa sentir na intervenção de Nhanderu: afinal, não é do corpo despedaçado do pássaro mítico que se originam as diversas espécies, mas da ação de Nhanderu.

Pelo visto até aqui fica claro por que a narrativa mbya desenvolve sua versão do cromatismo vinculando-o à capacidade de um pássaro copiador, amalgamando dessa forma a variação infinitesimal cromática com o caráter multiplicador de um imitador ${ }^{11}$ : a «maleficência original » (ibid., p. 321) do cromatismo e da cópia exagerada é para os Mbya uma e a mesma coisa. Igualmente às narrativas que descrevem as ações imitadoras de Xariã/Anhã, nesta narrativa é efetuada a diferenciação em espécies similares, mas de um modo diferente: o pássaro guyra rembykyra 'a 'eỹ imita por antecipação, sendo ele próprio exagerado, produzindo as diversas espécies por fragmentação do significante. Afinal, é ele mesmo, por definição, a conjunção do discreto (um corpo/um canto). É a partir de sua anulação por fragmentação que se produzem as diferentes espécies e cantos.

Depois do dito até aqui, é interessante notar que o caráter maléfico dos pequenos intervalos seja ressaltado no pensamento mbya através de seu léxico. Como vimos, a inferioridade do «muito e uniformemente », o cromático de caráter maléfico, em oposição ao valor dado ao « contraste e diferenciação », o diatônico, é formulado justamente no binômio em que « vai » se opõe a « para ». Tudo se passa como se essa oposição lexical fosse uma realização, no plano da linguagem, da verdadeira categoria ameríndia do entendimento que seria o cromatismo (Lévi-Strauss 2011 [1971], p. 455).

\section{Aparência e duração}

Como vimos, a dualidade original/cópia adquire nas narrativas de Xariã/Anhã e em outros mitos guarani uma relação direta com a imitação pelo excesso. A relação entre original e cópia possui como correlato a noção de aparência, que poderíamos definir como a discordância que resta entre ambas. Nas narrações mbya, essa discordância pode chegar a adquirir um caráter generalizante quando

11. Foi um dos avaliadores anônimos deste artigo quem chamou nossa atenção sobre essa semelhança. Aproveitamos para agradecer seus comentários que nos permitiram aprofundar alguns argumentos, entre outros: o do pássaro como copiador antecipado e a homologia dos pares cromatismo/variação infinitesimal, cópia/multiplicação. 
foca o contraste entre a primeira terra e sua relação com o mundo atual dos Mbya, motivo que passamos a focar a seguir. Ele nos levará à relação dos não indígenas com a noção de cópia.

A oposição entre os seres da primeira terra e as cópias é narrada, por exemplo, pelos Mbya do Paraguai, com os quais trabalhou Cadogan (1997 [1959], p. 50-53). Eles contam que os seres que se encontravam na primeira terra eram: a serpente originária, primeiro ser que sujou a morada terrena do verdadeiro Pai Nhamandu; a pequena cigarra vermelha, primeira que cantou na terra; o grilo, o coleóptero senhor das águas, o nhambu vermelho, a coruja, e finalmente o tatu. Todos esses seres são qualificados como « verdadeiro(s) » ( $a$ 'ete $\left.v a^{\prime} e^{12}\right)$, distinguindo-se dos exemplares que existem atualmente « em nossa terra » (nhandeyvypy) que são caracterizados como sendo somente « imagem » (-a 'angaa). Cadogan ressalta que animais como a tapira e o taiaçu também seriam originários e « no son seres humanos que sufrieran metempsicosis, sino aparecieron ya en su forma actual en la primera tierra » (ibid., p. 61).

Outros Guarani não são menos restritivos do que aqueles com os quais Cadogan trabalhou e para os quais a totalidade do mundo atual pode ser conceitualizada como uma « imagem » ou « cópia » do primeiro mundo. Assim, os Guarani do sul do Brasil relatam a existência de -a'angaa de humanos, animais e plantas no mundo atual, na terra má (yvy vai), a parte destrutível do cosmos: por isso as aldeias podem ser entendidas como lugares onde habitam « cópias ou imagens imperfeitas e perecíveis de seres que existem nos outros planos superiores a este » (Mello 2006, p. 256), sendo que os seres criados pelos deuses para morar nesta terra atual (yvy vai) são duplos das formas « perfeitas » que se encontram no outro plano do cosmos.

Não é diferente o que afirmam os Mbya que habitam no Uruguai: as coisas existentes em yvy axy, a «terra imperfeita », que quer dizer para os Mbya « nossa localidade atual », são - a'angaa « aparência » (Rodríguez 2003, p. 261). Já os Mbya que habitam no Rio de Janeiro chamam a terra atual de yvy reko axy, « terra imperfeita, dolorosa », e enfatizam seu caráter temporal: Quando os discursos mbya opõem a qualidade « dolorosa » (-axy) da vida terrena ao modo de vida terrena ao modo de vida das divindades, evidencia-se o lugar de imperfeição: aqui na Terra « tudo acaba », dizem os Mbya, enquanto o que pertence a Nhanderu e à sua morada « não tem fim » (Pissolato 2007, p. 226-227).

Mais uma vez é na arte que essa oposição se observa com especial clareza. A oração de lamento ( $m b a^{\prime} e \tilde{a}^{\prime} \tilde{a}$ « esforço $\left.{ }^{13} »\right)$ executada pelo mbya Lorenzo Ramos, de Misiones, redireciona justamente uma das oposições do mito sobre os seres da primeira terra se valendo do contraste animais verdadeiros (a'etei $i$

12. De -ete « verdadeiro » +va'e, nominalizador com um sentido de « aquele(s) que ».

13. Sobre esse gênero ver H. Clastres (2007 [1975], p. 133-134). 
va'e)/figurações artesanais dos animais. Nesse lamento, os animais e os outros seres são substituídos pelos «bichinhos » (vixo ra'angaa) do artesanato, as conhecidas talhas elaboradas geralmente com madeira leve de caixeta, fonte importante de renda atualmente para muitos guarani. Lorenzo Ramos denomina os animais representados nestas mercadorias como « simples representações 》 (-a'angaa), em oposição aos « verdadeiros » (a'etei i va'e). Outras mercadorias produzidas pelos Mbya para venda, como os arcos (guyrapa) e as flechas ( $u^{\prime} y$ axĩ) e também mercadorias compradas para consumo, como a farinha ( $u$ 'i ixĩ), são aqui qualificadas do mesmo modo que a vida na terra atual, « imperfeita » ou « dolorosa » (reko axy) (Ramos 2006 [1984], p. 21-30).

O lugar de mediação dessas pequenas esculturas realizadas para venda pelos guarani fica claro na fala de Célia mbya: «Os deuses já sabiam que a gente ia precisar vender artesanato, que as matas iriam acabar. Então por isso os deuses nos deram essa habilidade de seduzir os brancos com bichinhos de madeira, pra vender e não morrer de fome » (Araújo, Carvalho e Carelli 2011, p. 144).

Portanto, a cópia se opõe, em sua temporalidade existencial, ao eterno. A morada terrena atual, de existência pós-diluviana (que está em oposição à também pós-diluviana e convencionalmente chamada Terra sem Males e à primeira terra antediluviana) comporta, em sua definição, uma correspondência com um mundo de cópias negativamente valorado. O interlocutor mbya de Rodríguez expressa esse fato mediante um aforismo que sintetiza de modo especialmente clarividente o valor espaço-temporal e moral da cópia: « Este mundo es copia, por eso hay maldad » (2003, p. 259).

Assim, entende-se que yvy mba'e megua seja traduzido como «o espaço humano », mas também como « a terra imperfeita » (P. Clastres 1990 [1974], p. 60). Já em apapocuva, mbaé megúa é como eram chamadas as catástrofes (Nimuendaju 1987 [1914], p. 68-69). Mas é a tradução de Hélène Clastres a que junta os dois sentidos relacionados neste texto, quando menciona que o sentido forte de mba'emeguä seria « imitação bufa » (2007 [1975], p. 120). Para os Kaiowa, ma'ëmegwá designa « todos os tipos de males » (Garcia 2003, p. 350-351).

$\mathrm{O}$ traço enfatizado da mitologia do primeiro mundo e da terra sem males é a duração das qualidades em um eixo diacrônico, a constância em oposição à efemeridade. Tal mitologia opera com um código geográfico. É por isso que os seres e modos de existir próprios da (ou predominantes na) terra atual são qualificados como corruptíveis, de existência efêmera.

$\mathrm{Se}$, como vimos anteriormente na narrativa registrada por Cadogan, a oposição entre « original » e « cópia » apresenta uma homologia com a oposição de localização dos seres na terra atual versus na primeira terra (ou na continuação qualitativa desta: na terra paraíso), na série de mitos sobre as cópias de Xariã, a oposição se estabelece tanto por quem produz, se o produto é obra de Nhanderu ou de Xariã, como pelas qualidades do produto. 


\section{Quem consome a produção de Xariã é jurua (não indígena)}

Que lugar ocupam os não indígenas em relação a esse par originário/cópia? Efetivamente, os não indígenas têm uma relação específica tanto com esta mitologia da transfiguração do mundo atual que acabamos de comentar como com as narrativas de Xariã/Anhã que examinamos na primeira parte deste texto. O mundo atual é um mundo de aparência, de meras cópias, de coisas que perecem. Andrés, o interlocutor mbya de Rodríguez, dá um exemplo dessa relação entre os não indígenas e o mundo das cópias: « El mundo en que vivimos está lleno de copias ( $\mathrm{ra}^{\prime}$ 'angaa), solo que el Juruá da a las cosas un valor eterno. El automóvil es por ejemplo una copia, tiene una duración determinada y llega un momento que se rompe » (Rodríguez 2003, p. 253). Por isso, em São Paulo, os Guarani dizem que os Juruá são chamados na opy como « os que vieram do nada $»:$ « [...] eles têm poder nesta terra, onde tudo estraga, acaba, vira nada, marã, diferentemente da terra divina de onde vêm e para onde retornará o nhe'e dos Guarani » (Macedo 2009, p. 263). Os não indígenas acreditam em um mundo de ilusões e de coisas perecíveis e são donos deste mundo de cópias.

Estas duas mitologias, por um lado a da cópia excessiva de Xariã e por outro a da réplica enfraquecida que compõe o mundo perecível terreno, podem complementar-se em uma só narrativa, operando uma intersecção entre os dois esquemas míticos, como quando Nhanderu Pa'i criou a laranja verdadeira e, querendo fazer o mesmo, Xariã criou as laranjas amargas. As verdadeiras laranjas estão no paraíso de Nhanderu, sendo que a laranja que existe nesta terra é somente uma imagem (-a'angaa) da original (Gamba 2003, p. 77-78).

A narrativa que trata da origem de cestos que serão utilizados de maneira diversa, ou para autoconsumo pelos Mbya ou para fins de comercialização tendo como público alvo os não indígenas, estabelece uma dupla conexão metonímica: as criações sóbrias remetem a si mesmos, os Mbya, enquanto as cópias excessivas remetem ao gosto daqueles outros que designam como Juruá, os não indígenas ou estrangeiros. Como discorre Assis:

Os Mbyá possuem vários relatos míticos em que apontam os Juruá como seres bárbaros ou inferiores, um grupo que é o seu oposto. A destinação dos ajaka decorados com motivos complexos para a comercialização com a sociedade englobante está intimamente associada com a homologia que muitas vezes se faz entre Charĩa [Xariã] e jurua. Foi Charĩa [Xariã] quem criou os motivos complexos e contrariou o que foi estabelecido por Nanderu. Perumi, argumentando sobre as distinções entre Mbyá e Juruá, afirmou que « Juruá é como Charĩa, cria como ele ». Juancito foi mais enfático em um diálogo na Lomba do Pinheiro (1996): « Charĩa e Juruá é tudo a mesma coisa ». (2006, p. 276)

A associação entre Xariã e os não indígenas é recorrente e referida de várias formas pelos Mbya. Os Mbya do Rio Grande do Sul, por exemplo, caracterizam 
a música jurua como ligada a Anhã ou ao -jepota ${ }^{14}$ (Stein 2009, p. 75, 190), outros consideram seu esporte por excelência, o futebol, da mesma forma (Rodríguez 2003, p. 224). Em várias versões do mito de Sol e Lua anotadas por Litaiff (1999), os jaguares que devoram a mãe deles são identificados, ou pelo menos congruentes, com Anhã. Na versão narrada por Kandino, de Salto do Jacuí (Rio Grande do Sul), os jaguares são substituídos por jurua (Assis 2006, p. 277).

Além de seres predadores, os jurua são demograficamente numerosos, existindo em quantidade excessiva. Por isto são chamados de heta va'e kuery « aqueles que são muitos » (Ladeira 2007, p. 40), ao passo que os Mbya paraguaios já se autodesignaram como ore, yvára tyre 'y mbovy $i$ : « nosotros, algunos pocos seres que vivimos alejados de la divinidad » (Cadogan 1997 [1959], p. 45). Partindo desta oposição geral, os Mbya não duvidam de seu vínculo com a divindade, ainda que atualmente despossuídos dela. Os brancos, excessivos em vários sentidos, são criaturas de Xariã. Assim, os Mbya (« mbwihas ») com os quais trabalhou Vellard no Paraguai indicaram que Oreru ${ }^{15}$ (i.e. Nhanderu) morava ao sul ${ }^{16}$, « si loin qu'il ne peut s'occuper des hommes de façon bien attentive » (Vellard 1939,p. 169). Ele é o criador dos Mbya e de outros índios, mas não dos brancos (ibid.: p. 168). Para Mariano Aguirre de São Miguel das Missões (Rio Grande do Sul), os Mbya são « os verdadeiros filhos de deus » (Moraes 2010, p. 58,174), sendo que certas vezes Xariã é identificado como criador dos não indígenas: « Segundo os Mbya, Sariá [Xariã] (que pode ser comparado com o diabo) faz tudo ao contrário de Ñanderu (principal divindade Mbyá-Guarani). Sariá cria corpos pesados, enquanto Ñanderu cria corpos perfeitos. Ñanderu criou os Mbyá, enquanto Sariá criou os juruá » (paráfrase de Rodríguez em Tempass 2005, p. 102, n. 67). A confirmação desta ideia encontra-se em uma narrativa coletada em Araponga (Rio de Janeiro):

Augustinho contou que nhanderu soprou e com isso nasceu o Guarani. Então Anhã viu isso e também soprou, veio um animal, não lembro qual, parece porco ou ovelha. Nhanderu soprou e veio $k a$ 'a (erva mate), aí anhá viu aquilo e soprou também, e veio jurua. Então veio essa separação. Esse Guarani que nhanderu soprou se tornou deus, não morre mais, é eterno. E esse jurua também não morre mais, é eterno, tornou-se deus também. Esse jurua gerou uma grande árvore e nela criaram-se muitas lagartas. Essas lagartas vieram para o mundo transformadas em jurua. (Macedo 2009, p. 265)

14. Sedução e transformação em animal.

15. Oreru, que significa « nosso pai » assim como Nhanderu, sendo que o « nós » de ore exclui aquele com quem se fala enquanto o «nós » de nhande é um pronome que inclui aquele com quem se fala.

16. Na maioria das etnografias sobre os Mbya Nhanderu reside ao Leste. 
A presença das lagartas -jurua não é casual, pois esses insetos encerram em si próprios as características de número (multidão), imitação, transformação e voracidade que vimos analisando ao longo das páginas anteriores. Como é sabido, as lagartas são extremamente vorazes e destrutivas, responsáveis pelas pragas que atacam diversas espécies de plantas. Muitas delas venenosas e coloridas, as lagartas são cópias de si mesmas (algumas espécies formam filas compostas por uma multidão de indivíduos, formando uma espécie de lagarta gigante) e ao mesmo tempo imitações parciais das plantas que devoram ${ }^{17}$.

Cópias de uma cópia, fruto da ação do imitador Anhã, o jurua sintetiza bem o mundo invadido pelas cópias que os Mbya habitam no presente. Mas não custaria perceber nessa relação um componente histórico, pois vale a pena lembrar que as reduções jesuíticas, onde aproximadamente 150.000 guarani viveram nos séculos XVII e XVIII antes de sua dissolução, foram dominadas por uma exacerbada atividade copista. Como registra Oliveira: « Sabe-se, mediante a documentação existente, que os indígenas não receberam instrução de técnicas de desenho, não estudaram com modelos vivos e não conheceram outra disciplina didática senão a cópia » (2013, p. 170).

Os jurua conformam uma multidão, como as lagartas; como elas, facilmente podem arrasar a floresta e se caracterizam igualmente pela produção de objetos em série. Os Mbya não só vivem longe dos deuses como habitam um mundo repleto de cópias. Poderíamos nos perguntar até que ponto o ascetismo ritual mbya não seria tanto um movimento em direção a seus deuses como a realização de um distanciamento desse mundo de cópias asfixiante dominado pelos jurua. O acuamento territorial e a devastação que cerca os territórios atualmente habitados pelos mbya faz da identificação dos jurua com as lagartas algo mais que uma metáfora.

\section{A diferença que faz a diferença}

É hora de recapitular e concluir. Partindo da análise das narrativas mbya pudemos verificar a existência de vários campos semânticos congruentes com a oposição Nhanderu/Xariã: no domínio da arte, dos desenhos, dos temperamentos,

17. A relação das lagartas com a cópia e a imitação aparece bem expressa no seguinte extrato extraído de um informe da Secretaria de Saúde do Paraná (Brasil): « As lagartas (taturanas, orugas ou lagartas de fogo), medem de 6 a $7 \mathrm{~cm}$ de comprimento, têm o corpo revestido de espinhos ramificados (semelhante a um pinheiro) dispostos ao longo do corpo. A cor geral é marrom-claro-esverdeada ou marrom amarelada, com três listras longitudinais de cor castanho-escuro. Há uma pequena mancha branca de contorno irregular no dorso do terceiro segmento torácico. São larvas que vivem agrupadas, alimentando-se de folhas durante a noite. Quando em bloco, imitam o tronco da árvore parasitada, descendo em bloco para as partes mais baixas onde repousam durante o dia » (Secretaria de Saúde do Estado do Paraná, consultado em 18/09/15). 
da cosmografia, entre outros. Vimos também como essa oposição articula materializações e conteúdos direcionados moralmente. Especialmente importante pareceu-nos o lugar cosmologicamente marcado que ocupa o não indígena e suas produções, identificado com Xariã, a criação exagerada, a cópia desviante. Como esse não é o padrão ameríndio mais comum nas Terras Baixas da América do Sul, onde muitos componentes não indígenas são celebrados na constituição de um modo de ser propriamente indígena, cabe perguntar-se se a existência dessa conceitualização dualista recorrente e axiologicamente hierarquizada, orientada pela relação original/cópia, possui relação com a conhecida persistência guarani (Calavia 2004), isto é, com a capacidade que os Mbya demonstram para mediar suas relações de forma autônoma em contextos coloniais desfavoráveis. Experiência tanto mais singular em se tratando de um povo que, como é sabido, recebe há séculos o impacto colonial e as consequências de um processo (dito) civilizatório estratégica e hierarquicamente organizado.

Apesar desse contexto de luta desigual - ou devido a ele -, inconstância e persistência formaram durante todo esse tempo duas caras da mesma moeda. Carlos Fausto (2005), em um texto em que ressalta o papel da memória e do esquecimento na constituição da tradição histórica guarani, resume, para dissolvê-los, esses dois estereótipos mais recorrentes referidos aos Guarani: por um lado, certa vulgata jesuítica clássica que os retratou como dóceis e especialmente receptivos ao projeto evangelizador e « civilizador »; por outro, a imagem dos Guarani como povo irredutível e conservador, detentor de uma cosmologia milenar, persistente e tradicionalista, « vontade tão férrea de manter em segredo a parte sagrada de seu ser » como escreveu Clastres (1990 [1974], p. 10).

Em vez de assumir esses estereótipos ou tomar partido por um ou outro, Fausto desloca a problemática ao enfatizar tanto os processos nativos de redefinição conceitual e transformação das práticas como os contextos sócio-históricos, dos quais não se pode excluir a experiência missionária dos Guarani nem os contatos fluidos que eles mantiveram - e mantêm até o presente - com os coletivos não indígenas. Para o argumento central deste texto é especialmente relevante a reflexão do autor sobre o processo de « desjaguarificação », resumido aqui a partir de um comentário sobre a narrativa Ava-katu-ete dos gêmeos: « Cuando Kuarahy se estaba yendo iba haciendo todas las cosas de esta tierra, hacía un animal, el Añag inventaba la forma de cazarlo » (Bartolomé 1977, p. XXVI). Fausto comenta:

A predação cinegética aparece, pois, não como um dado a priori ou como uma condição dada pelo demiurgo, mas sim como uma artimanha de seu rival canibal. O mito parece querer marcar, pois, a disjunção absoluta entre a divindade e a predação, de tal forma que o xamã está livre para operar na relação com seres divinos que não são predadores à maneira dos espíritos familiares de xamãs amazônicos. (2005, p. 399) 
Resumindo um dos argumentos principais de Fausto, a distribuição dos predicados vegetarianismo/predação no par Kuarahy/Añang faz parte de um processo de desjaguarificação dos Guarani, processo relacionado com a experiência colonial e o projeto missionário. Essa perspectiva Ava-katu-ete é congruente com a dualidade que exploramos neste artigo para os Mbya, onde a predação é entendida como uma forma exagerada de se relacionar com os animais: vimos, no mito narrado por Davi, que foi Anhã quem criou « sobretudo os ferozes », isto é, os mais identificados com atitudes predadoras; ou então, que Xariã, querendo copiar a abelha « sem ferrão » jataí (jate ’i) feita por Kuaray, só conseguiu fazer uma vespa amarela « que pica dolorosamente » (kava vaju) (Gamba 2003, p. 74-75). Como afirma Fausto, trocando o canibalismo pelo amor, a experiência da redução perdurou como tradição indígena: « Sin embargo, no hay aquí ningún aspecto de inautencidad, pues esa capacidad de inscribirse por el revés, haciendo sí mismo otro, es, por cierto, característicamente indígena » (2009, p. 13). Mostramos que nessa posição de repulsa à predação, significada através de certos animais e outros seres, não há somente uma substituição do canibalismo pelo amor, mas a elaboração de uma dualidade não paritária que faz vários seres (excessivos) serem desprezados.

Das conclusões de Fausto é possível extrair um ensinamento geral exemplarmente traçado a partir dos dados guarani: memória e esquecimento possuem um valor estruturante equivalente nos processos de constituição da tradição. Sem dúvida, os diferentes grupos guarani incorporaram parcialmente inúmeros elementos através de sua experiência missionária e de contato - referências rituais à missa católica, personagens jesuíticas incluídas nas narrativas, musicalidades, percepções da predação, entre outros. Entretanto, e à diferença de outros coletivos indígenas, os Mbya deram continuidade ao longo dos séculos a sua língua, seus deuses, seus modos de vida, e a um valor diferencial pelo qual zelaram tenazmente por obra e omissão (pensemos, por exemplo, na importância que o silêncio e o segredo possuem entre os Guarani, autênticos modos de comunicação).

Nesse contexto, as narrativas que selecionamos e reunimos neste artigo permitem visualizar uma torção mbya que nos parece fundamental destacar: o valor diferencial e cosmologicamente fundado conferido às criações de Nhanderu e às ações de Xariã. À memória e ao esquecimento, os Mbya acrescentaram o valor de um julgamento que age por conta própria, conforme parâmetros mbya de experiência e avaliação histórica.

Viveiros de Castro fez um comentário sobre História de Lince que, mutatis mutandis, poderia ser aplicado à coalescência Xariã/não indígena afirmada pelos Mbya: « O desequilíbrio ou abertura intensiva que é uma propriedade constitutiva da estrutura [...] atinge o que se poderia chamar de maneira jocosamente hegeliana de consciência de si » (2008, p. 21). Tomando como um conjunto as 
narrativas mbya e suas glosas, pode-se evidenciar com mais clareza essa consciência de si, ou melhor, essa « consciência do outro » situada justamente em um desequilíbrio alumbrado na fatalidade da cópia. Como vimos, as narrativas mbya articulam uma dualidade que englobou certos aspectos do mundo não indígena associado ao desvio do caminho originário definido por Nhanderu. Esse mundo é relacionado com a falta de acesso às coisas permanentes, originárias, do mundo verdadeiro. Poderíamos nos perguntar se não é através do exercício da forma de um dualismo hierarquizado presente na cosmologia guarani que o Outro permanece como tal excluído do campo de ação de Nhanderu e por isso desviado do caminho dos Mbya. Parece-nos que o lugar concedido ao mundo não indígena nessa separação entre criação original e imitação excessiva aponta justamente para o lugar mediado e não englobante dessa relação.

Com efeito, pensamos que do ponto de vista mbya Xariã e o homem branco caminham de mãos dadas, ao ponto de assemelharem imagens separadas (ou talvez deveríamos dizer confundidas) apenas por um fino espelho. Inscrita pelo avesso, a sobrevivência da experiência das reduções não excluiu a permanência de um desequilíbrio valorativo que, tendo que escolher, não hesitou em deixar para Xariã, para o « diabo », os frutos azedos desse mundo espelhado, ora não indígena, ora diabólico, ora ambos ao mesmo tempo. *

* Manuscrit reçu en novembre 2012, accepté pour publication en février 2016.

\section{Bibliografia citada}

Araújo Ana, Ernesto Carvalho e Vincent Carelli

2011, Vídeo nas Aldeias 25 anos: 1986-2011, Vídeo nas Aldeias, Olinda (PE).

Assis Valéria Soares de

2006, Dádiva, mercadoria e pessoa: as trocas na constituição do mundo social Mbyá-

Guarani, tese de Doutorado em Antropologia Social, Universidade Federal do Rio Grande do Sul, Porto Alegre.

Bartolomé Miguel Alberto

1977, Orekuera Royhendu (lo que escuchamos en sueños): shamanismo y religión entre los Ava-Katu-Eté del Paraguay, Instituto Indigenista Interamericano, México.

CADOGAN León

1997 [1959], Ayvu rapyta: textos míticos de los Mbyá-Guaraní del Guirá, Fundación

León Cadogán/Centro de Estudios Antropológicos de la Universidad Católica

(Ceaduc)/Centro de estudios paraguayos « Antonio Guasch »(Cepag), Asunción.

2011 [1992], Diccionario Mbya-Guarani-Castellano, Ceaduc/Cepag, Asunción.

Calavia Oscar

2004, « La persistencia guaraní. Introducción », Revista de Indias, 64 (230), p. 9-14.

Clastres Hélène

2007 [1975], Terra sem mal, Tapé, Corumbiara/Roraima. 
Clastres Pierre

1990 [1974], A fala sagrada: mitos e cantos sagrados dos indios Guarani, Papirus, Campinas (SP).

Dolley Robert

2013, Léxico guarani, dialeto mbya: com informações úteis para o ensino médio, a aprendizagem e a pesquisa linguística, Associação Internacional de Linguística - SIL Brasil, Cuiabá (http://www-01.sil.org/americas/BRASIL/publcns/dictgram/ GNDicInt.pdf).

Fausto Carlos

2005, « Se Deus fosse jaguar: canibalismo e cristianismo entre os Guarani (séculos XVI-Xx)», Mana, 11 (2), p. 385-418.

2009, « Prefacio - El reverso de Sí », in Guillermo Wilde, Religión y poder en las misiones de guaraníes, Sb, Buenos Aires, p. 9-14.

Gamba Carlos (ed.)

2003, Tatachina tataendy: la neblina el fulgor. Nuevos textos míticos de los Mbyá, Cepag, Asunción.

GARCIA Wilson

2003, Nhande rembypy: nossas origens, Editora UNESP, São Paulo.

Godoy Gustavo

2011, Formas, cópias, regressões e fragmentações em mitologias ameríndias, Trabalho de conclusão de curso, Universidade Federal do Paraná, Curitiba (Brasil).

KuKumasu James e Kiyoko KaKumasu

2007 [1988], Dicionário por tópicos kaapor-português, Associação Internacional de Linguística - SIL Brasil SIL, Cuiabá (http://www-01.sil.org/americas/brasil/ publens/dictgram/UKDict.pdf).

LADEIRA Maria Inês

1984, « Aldeias livres Guarani do litoral de São Paulo », in John Monteiro, Lúcia Helena Rangel, Lúcia Andrade, Mara Luz, Ronaldo Gomes, Silas Guerriero e Silvia Helena Borelli (orgs.), Índios no Estado de São Paulo: resistência e transfiguração, Comissão Pró-Índios de São Paulo, Yankatu, São Paulo.

2007, O caminhar sob a luz. Território mbya à beira do oceano, Editora UNESP, São Paulo.

2008, Espaço Geográfico Guarani-Mbya: Significado, constituição e uso, Editora UNESP, São Paulo.

LÉvi-Strauss Claude

2004 [1964], O cru e o cozido (Mitológicas 1), Cosac \& Naify, São Paulo.

2011 [1971], O homem nu (Mitológicas 4), Cosac \& Naify, São Paulo.

2012 [1973], Antropologia estrutural dois, Cosac \& Naify, São Paulo.

LiTAIFF Aldo

1999, Les fils du soleil: mythes et pratiques des indiens Mbya-Guarani du litoral du Brésil, tese de doutorado, Departamento de Antropologia, Université de Montréal, Montréal.

MACEDo Valeria

2009, Nexos da diferença: Cultura e afecção em uma aldeia guarani na Serra do Mar, tese de doutorado, Programa de Pós-Graduação em Antropologia, Universidade de São Paulo, São Paulo. 
Mello Flávia Cristina de

2006, Aetchá Nhanderukuery Karai Retarã. Entre deuses e animais: xamanismo, parentesco e transformação entre os Chiripá e Mbyá Guarani, tese de doutorado em Antropologia Social, Universidade Federal de Santa Catarina, Florianópolis.

Montoya Antonio Ruiz de

1639, Tesoro de la lengua guaraní, Juan Sanchez, Madrid.

Moraes Carlos Eduardo

2010, A refiguração de Tava miri: São Miguel na memória coletiva dos Mbyá-guarani nas Missões/RS, Brasil, programa de Pós-Graduação em Antropologia Social da Universidade Federal do Rio Grande do Sul, Porto Alegre.

NAvarro Eduardo de Almeida

2013, Dicionário de tupi antigo: a língua indígena clássica do Brasil, Global, São Paulo.

Nimuendaju Curt

1987 [1914], As lendas da criação e destruição do mundo como fundamentos da religião dos Apopacuva-Guarani, HUCITEC/Editora da Universidade de São Paulo (Coleção ciências sociais), São Paulo.

OLIVEIRA Marilda

2013, Identidade e interculturalidade: história e arte, Editora da Universidade Federal de Santa Maria, Santa Maria.

Pereira Vicente

2010, « Mbya reko e elementos urbanos: encontros dos Guarani Mbya com a cidade em contextos distintos de ocupação no Estado do Rio de Janeiro », Intratextos, número especial 01, p. 85-102.

Pissolato Elizabeth

2007, A duração da pessoa: mobilidade, parentesco e xamanismo mbya (guarani), Editora UNESP, São Paulo/NuTI, Rio de Janeiro.

RAMOs Lorenzo

2006 [1984], « Mba’e ã’ã - Esfuerzo (Plegaria) », in Lorenzo Ramos, Benito Ramos e Antonio Martinez, El canto resplandeciente: Ayvu rendy vera, Del Sol, Buenos Aires, p. 21-30.

RoDrigues Ayron

1984-1985, « Relações internas na família lingüística tupi-guarani », Revista de Antropologia, 27-28, p. 33-53.

RoDRíGuEz José

2003, Índios num país sem índios: a estética do desaparecimento. Um estudo sobre as imagens índias e as versões étnicas no Uruguai, tese de doutorado, Programa de Pós-Graduação em Antropologia Social da Universidade Federal do Rio Grande do Sul, Porto Alegre.

STEIN Marília

2009, Kyringüe mboraí: os cantos das crianças e a cosmo-sônica Mbyá-Guarani, tese de doutorado em Música, Universidade Federal do Rio Grande do Sul, Porto Alegre.

TEMPAss Mártin

2005, Orérembiú: a relação das práticas alimentares e seus significados com a identidade étnica e a cosmologia Mbyá-Guarani, dissertação de mestrado, Programa 
Gustavo Godoy e Miguel CARID

de Pós-Graduação em Antropologia Social, Universidade Federal do Rio Grande do Sul, Porto Alegre.

VELLARD Jehan

1939, Une civilisation du miel : les indiens guayakis du paraguay, Gallimard, Paris.

Viveiros de Castro Eduardo

1986, Araweté: os deuses canibais, Jorge Zahar, Rio de Janeiro.

2008, « Claude Lévi-Strauss, fundador do pós-estruturalismo », Tempobrasileiro, 175 , p. 5-31. 